to realize also, with equal clearness, the more orthodox points of view of Einstein, Bohr, Dirac and others; to see wherein the outlooks differ and how they can be reconciled; and to re-express the work of all in terms compellingly obvious, so that the contribution of Eddington can be assessed at its true value and physicists everywhere united on a common front in an immensely strengthened position for apprehending and solving the problems that remain. There can be no doubt, I think, that such a man would render to physical science the greatest benefit possible to it at the present time; yet the world of physical science has no provision for acknowledging such a benefit. For slightly inferior intellects there are Copley Medals, Orders of Merit, Nobel Prizes and the like, but for him, nothing. Like Bunyan's Interpreter, he makes pilgrimage possible, and is heard of no more. He has added nothing to knowledge; he has not discovered a single new fact of observation or revealed a single relation between measured quantities or introduced a single new concept into the subject. Everything of that kind has been done by others before him; he has simply brought to light what they have done. I submit that a condition in which clear-sighted understanding is esteemed so lightly in comparison with blind achievement is not one which ought to be regarded without misgiving.

If we try to look into the immediate future the misgiving grows. We are about to experience a great increase of scientific activity. Existing universities are to be enlarged and new ones created, and we may look forward to a rapidly growing army of young workers, becoming more and more specialized as time goes on. Competition for entry to the Royal Society will be greatly intensified, and since entry is to be gained by doing things and not by knowing what one is doing, those who pause to reflect on the meaning of their work will fall behind in the race and remain outside. At the present time the Royal Society contains, chiefly among its older Fellows, somethough far too few-who have been able and willing to supplement their specialized work by giving attention to its wider implications. Through their labours and those of their forerunners the Society has supported research into the nature and history of science in various ways, for which we cannot be too thankful. But such efforts will almost inevitably decrease, and while I do not believe that the race of historians or philosophers of science will die out, the conditions of the time will be such that they will be automatically segregated. Instead of a vigorous critical school growing up within and promoting the welfare of science, we are likely to have an artificially stunted one growing up without and conflicting with it. Such a prospect bodes little good either for science or for the community as a whole.

What are the omens on the other and brighter side? Apart from the sporadic and incalculable influence of exceptional individuals, I know of only one. I said just now that our hypothetical interpreter of modern physics could receive no recognition of his service. I was wrong. If he cared to fulfil certain other conditions well within his scope, he could earn an M.Sc. degree of the University of London in the history and philosophy of science. That may seem something of an anti-climax, and if that aspect of it should tend to direct someone towards a rectification of the situation I would not wish to temper the feeling, but it is not the aspect I want to present now. The
Department of History and Philosophy of Science at University College was founded in 1923. During the sixteen years prior to its suspension at the outbreak of war, 173 students, all graduates in science, took its courses, and 84 M.Sc., 18 Ph.D., and 2 D.Sc. degrees were awarded. In the first and second year since revival, 10 and 37 students, respectively, have been enrolled. From the first the courses were planned on admirable lines, and the foundations of a uniquely valuable Department have been laid. The staff, originally comprising one part-time teacher, has grown to four full-time and one part-time teachers, with assistance from other teachers of the University who have special knowledge of the history of their own science. The University, fully aware of the need for such a Department, has given it high priority in the forthcoming expansion. It needs now but the devoted and efficient service of its members to realize at least some of the high hopes that went to its establishment.

The fact that, by the award of higher degrees within the Faculty of Science, a great University recognizes the attainment, by those trained in the practice of science, of some understanding of what they have been practising has, I think, an importance out of all proportion to the present magnitude of the effort. However inadequate it may be, its influence is genuine. It begins to create within the scientific world an atmosphere in which true science, become self-conscious, can flourish and spurious science decay. As the community is called upon to consider how it is to adjust itself to a world in which the influence of science grows ever greater, it infuses into society a leaven of men and women who are not deceived by the momentary appearance of a movement which, after taking two thousand years to prepare itself, has been gathering momentum for the last three hundred years. The example of London may in time be followed by other universities until gradually the critical spirit becomes an integral part of science everywhere, and the mad rush along the primrose way to the everlasting bonfire is changed to an ordered movement towards a preconceived and deliberately chosen goal. Provided that the effort has not come too late, it may well prove in the end to have started the process which will convert science from a mysterious menace to a comprehended blessing. Such, at any rate, is its potentiality; it remains to make it actual.

1 "The Nature of the Physical World", by Sir Arthur Eddington, p. 275. "The Social Function of Science", by J. D. Bernal (Routledge, 1939).

\section{THE SPARK DISCHARGE}

A DISCUSSION on "The Spark Discharge" was A held at a meeting of the Physical Society in the Physics Department, Imperial College of Science and Technology, London, on April 23. The opening paper was presented by Prof. L. B. Loeb, of the Physics Department, University of California, Berkeley. Other invited speakers were Prof. J. M. Meek and Dr. T. E. Allibone.

In a survey of certain aspects of the mechanism of development of spark discharges, Prof. Loeb made particular reference to the distinctions between the Townsend theory of the spark and the streamer theory of the spark, as proposed by Loeb and Meek. The Townsend theory is now considered to apply only to the breakdown of short gaps in gases at low 
gas pressures, whereas the streamer theory applies to the breakdown of gaps of the order of $1 \mathrm{~cm}$. or more at about atmospheric and higher pressures.

According to the Townsend theory, the breakdown of a gap occurs when $\gamma e^{\alpha d}=1$, where $\alpha$ is the number of pairs of electrons and positive ions created per centimetre in the direction of the electric field by a single electron, $\gamma$ is the chance that a positive ion striking the cathode will liberate a secondary elec. tron, and $d$ is the gap-length. This expression enables the breakdown voltage of a gap to be determined from the known measured values of $\alpha$ and $\gamma$ as functions of voltage gradient and gas pressure. As in individual cases the values of $e^{a d}$ and $\gamma$ fluctuate considerably about their mean measured values, variations in the breakdown voltage may be expected to occur. Prof. Loeb showed that the resulting relation between the applied voltage and the probability of a spark is in agreement with experimental observations of the time-lags to breakdown, and also establishes the basis for the correct evaluation of the threshold sparking voltage. Further, an expression can be deduced to relate the total observed time-lag with the formative and the statistical time-lags.

The streamer theory involves the same quantity $e^{\alpha d}$ in conjunction with a new parameter $\gamma^{1}$, analogous to the Townsend $\gamma$, but depending on photon production in the head of an electron avalanche, and the photon absorption in the high-field region surrounding the avalanche head. Here again an expression can be deduced for the observed time-lag of spark development in relation to the statistical and rormative time-lags, and Prof. Loeb stressed the need for further experimental measurements of these quantities, particularly in order to determine the transition between the Townsend and the streamer mechanism.

The Townsend mechanism depends on the numbers of ions in the gap and is in agreement with Paschen's law, which states that the voltage required to cause breakdown of a uniform gap is a function of the product of gap-length and gas pressure. Meek's criterion for a spark, as based on the streamer mechanism, depends on the ion concentration in an individual electron avalanche, and predicts small deviations from Paschen's law. This anticipated failure of Paschen's law has been confirmed by recent measurements of the breakdown of uniform flelds at high voltages, for wide ranges of gap-length and gas pressure, and Prof. Loeb showed that the experimental results accord in principle with those expected from Meek's theoretical calculations.

The streamer process develops across the gap to form an ionized path or spark channel through which the external circuit discharges. The breakdown of the gap is then complete, and the voltage between the electrodes falls to a considerably reduced value corresponding to the voltage drop along the spark channel. Prof. Meek described some of the results obtained by Mr. J. B. Higham and himself in investigations of the voltage gradients and current densities in spark channels for gaps up to $100 \mathrm{~cm}$. in length in air and other gases. The various parameters are recorded either oscillographically or by photographic methods. In one of the records shown, for a spark in air carrying 100 amp., the voltage gradient at a time 1 microsec. after breakdown is 120 volts per cm., and at 50 microsec. is 25 volts per $\mathrm{cm}$. These values of voltage gradient are considerably greater than those for continuous arcs carrying the same current. Measurements of the spark diameter show that the channel expands during its early stages at a speed of the order of $10^{5} \mathrm{~cm}$. per sec., in accordance with the results obtained by Flowers. The current density in the channel is initially of the order of $10^{5} \mathrm{amp}$. per cm. ${ }^{2}$, but it decreases rapidly and, for a 400-amp. spark in air, is about $2 \times 10^{4}$ amp. per $\mathrm{cm} .^{2}$ at a time of 1.3 microsec. after breakdown. Some reeords have been obtained for sparks in which the growth of the channel is restricted by a surrounding glass tube. Other records were described for sparks in liquids; in one oscillogram shown, for a 250-amp. spark in water, the voltage gradient measured at a time 1 microsec. after breakdown was 1,200 volts per $\mathrm{cm}$.

Prof. Meek stated that in the measurements of current density the values given are determined on the assumption that the current is evenly distributed over the cross-sectional area of the spark. It is probable, however, that there are radial variations in the current density, and that the ion density and the current flow may be slightly higher near the centre of the spark than near the circumference. A further feature of spark channels is that emission of light persists for much longer times in certain parts of the channel than in others, so that the channel appears to break up into a series of discrete small regions of luminosity, in the manner similar to that of the occasionally observed phenomenon of 'bead lightning'. Prof. Meek referred to investigations of this persistence of luminosity which are now being made by Craggs and Hopwood.

The investigations by Schonland and his colleagues into the mechanism of development of lightning discharges were described by Dr. Allibone. By means of photographs obtained with a rotating film camera, Schonland has shown that the first stroke of a lightning discharge in open country is preceded by a streamer process known as a 'stepped leader stroke', which develops in a series of steps from cloud. to ground at a speed of about $1.5 \times 10^{7} \mathrm{~cm}$. per sec. When the leader stroke reaches ground, the main stroke travels up the pre-ionized channel which has been established between the cloud and the ground at a speed of the order of one tenth that of light. The large currents observed in lightning discharges flow during the passage of the main stroke. The second and subsequent strokes of a lightning discharge are each preceded by a 'dart leader stroke', which usually proceeds in a single flight from cloud to ground, at a speed of about $2 \times 10^{8} \mathrm{~cm}$. per sec., and follows the track traced out by the first stroke. After each dart leader there is a main stroke which develops from ground to cloud.

Rotating-camera studies have also been made for long spark discharges in the laboratory by Allibone and Meek, who have shown that considerable differences exist in the mechanism of development of long spark discharges in non-uniform fields between a point and a plane according to the polarity of the discharge. In a gap between a positive point and an earthed plane, a leader stroke develops from the positive point to bridge the whole gap, and the main stroke then takes place along the path traced out by the leader stroke. For a negative point and an earthed plane, the discharge is initiated by a negative leader stroke developing from the point; but, after this leader stroke has grown for only a short distance into the gap, a positive leader stroke develops from the earthed plane and the two leader strokes proceed towards each other to meet in the mid-gap region. The breakdown is completed by the passage of the 
main stroke along the track pre-ionized by the leader strokes. Considerable differences are observed in the characters of the positive and negative leader strokes. The positive leader stroke develops usually in a continuous manner, though steps occur when a high series resistance is included in the circuit, and these steps become more pronounced with decreasing gas pressure. The negative leader stroke develops in a series of sharply defined steps, and is accompanied by a considerable number of mid-gap streamers.

In all three papers it was evident that, although the various modern techniques of high-speed recording have yielded a considerable amount of experimental data concerning the development of spark discharges, there are still many aspects of the problem requiring further investigation. Also, while the mechanism of spark breakdown in uniform fields can now be explained in terms of fundamental processes, the interpretation of all observed sparking phenomena, particularly in non-uniform fields, is still by no means complete.

\section{TATA INSTITUTE OF FUND- AMENTAL RESEARCH}

$\mathrm{I}^{\mathrm{N}}$ India, where the number of institutions for research is very small, it is now keenly realized. that much greater attention must be paid to research, pure as well as applied, if India is to keep pace with the progressive nations of the world. A result of this new outlook and a welcome addition to such institutions is the newly established Institute for Fundamental Research, sponsored by the trustees of the Sir Dorabji Tata Trust and the Government of Bombay, with the subsequent support of the Government of India. The object is to create a centre for fundamental research, with particular reference to atomic physics and mathematics, and also to train the young scientific workers of India in these subjects.

Tatas, the biggest industrialists of India, have a long tradition of foresight and wisdom in the employment of their resources. To-day, 85 per cent of their capital is held in public trusts for benevolent projects, chief among which is the promotion of higher education and research. They were the pioneers in founding the Indian Institute of Science at Bangalore, the Tata Memorial Hospital for cancer and the Tata Institute of Social Sciences at Bombay. The Tata Institute of Fundamental Research is the newest institution which owes its existence to their enterprise and munificence.

Since 1942, the Sir Dorabji Tata Trust has supported a Cosmic Ray Research Unit headed by Prof. H. J. Bhabha, F.R.S., at the Indian Institute of Science, Bangalore. It was felt, however, that the modern demands of fundamental research in cosmic rays and nuclear physics could only be met by means of a separate institute devoted entirely to these subjects. The Cosmic Ray Research Unit of the Indian Institute of Science was moved to Bombay in 1945, and formed the nucleus around which the new project was built. As the construction of new buildings was not possible during the War, the Institute was housed in temporary premises. It was formally opened on December 19, 1945, by Sir John Colville, Governor of Bombay.

On that occasion, when inaugurating the Institute, Sir John Colville said : "India stands in urgent need of the speedy development of her resources, both agricultural and industrial. This can only be achieved with the aid of science. For modern industry and agriculture rest, to an ever-increasing extent, upon scientific foundations, and economic progress depends on continual advances in the field of fundamental research which provides the material on which the applied scientist can work." Sir John Colville further remarked that: "Applied research, designed to meet the practical needs of industry and agriculture, and carried on in the laboratories of Government research stations or by particular firms, is necessary. It is, however, increasingly recognized that research of a fundamental character, not directed towards specific practical objectives, is of vital importance, because of its fructifying and stimulating influence on applied research, which, without it, is bound to languish. Applied research, in fact, must be kept constantly refreshed by contact with the original work of the pure scientist."

During the first year of its existence it became clear that the new Institute would have to expand rapidly, and the necessary funds for this expansion were sanctioned by the Government of India through the Council of Scientific and Industrial Research. The Institute is to-day administered by an inde. pendent council on which the Government of India, the Government of Bombay and the trustees of the Sir Dorabji Tata Trust are represented. At present the Institute has chairs of theoretical physics, experimental physics, pure mathematics and astrophysics. Provision is also made for a visiting professorship so as to enable the Institute to invite distinguished men of science from abroad to work in the Institute for a year at a time. The Institute has also several readerships, and posts for research fellows and research assistants. A number of students are given liberal stipends to enable them to work under the professors of the Institute.

Since its start, the Institute has completed an experiment for measuring the intensity of the penetrating component of cosmic rays up to an altitude of $40,000 \mathrm{ft}$. In this experiment the intensity of cosmic rays penetrating $30 \mathrm{~cm}$. of lead was measured for the first time up to these altitudes. Several papers on the theory of the elementary particles and on new relativistic wave equations, on mathematical and statistics topics, have been published by members of the Institute.

The Institute will encourage to the utmost the exchange of scientific ideas. Recently a group of foreign men of science visited India as delegates to the Indian Science Congress, and the opportunity was taken to invite Prof. P. M. S. Blackett, of the University of Manchester, Prof. J. Hadamard, of the Institut de France, and Prof. S. S. Chern, of the Academia Sinica, as visiting professors to the Institute to deliver courses of lectures on their subjects.

The Council of Scientific and Industrial Research has decided that the Institute shall be the centre of all large-scale research in nuclear physics in India, and has sanctioned a scheme for the setting up, at the Institute, of a high-energy accelerator, capable of producing particles of energies up to $200 \mathrm{MeV}$. A team of ten investigators is being formed for this purpose. With the establishment of the high-energy accelerator, it is intended to lay down a long-range plan of nuclear research.

It is also likely that a small atomic pile will be set up at the Institute in the near future, which will provide further facilities for research in 